See Article page 153.

\section{Commentary: When the going gets... stuck}

\author{
Andrea Amabile, MD, and Arnar Geirsson, MD
}

Severe coronary artery calcification affects up to $20 \%$ of patients undergoing percutaneous coronary intervention, ${ }^{1}$ and a high burden of coronary calcium has been associated with increased risk of both procedural (eg, stent malpositioning, ${ }^{2}$ coronary perforation, ${ }^{3}$ and dissection ${ }^{4}$ ) and postprocedural (eg, intrastent thrombosis and restenosis ${ }^{5}$ ) complications.

In this frame, rotational atherectomy (RA) was introduced in the late $1980 \mathrm{~s}^{6}$ as an endovascular technique to ablate inelastic, endoluminal calcific debris by forward advancement of a rotating, diamond-tipped, abrasive burr. Although it was originally conceived as a generalized debulking strategy, RA became, over time, an elective preparatory step preceding balloon angioplasty and stenting in severely calcified atherosclerotic lesions.

Waterford and colleagues ${ }^{7}$ report the case of a patient with a history of coronary artery bypass grafting who underwent coronary catheterization 8 years afterward for recurrence of symptoms. The patient was offered RA for treating a calcified lesion in the mid segment of the left anterior descending artery, distal to the anastomotic site of the failed graft. After runs of ablation, the burr could not be pulled back from the coronary artery despite exhaustion of catheter-based removal techniques, and cardiac surgery consultation was required. After redo midline sternotomy, the authors were able to remove the burr through an already existing, guidewire-related perforation site at the distal left anterior descending artery, which was

\footnotetext{
From the Division of Cardiac Surgery, Department of Surgery, Yale School of Medicine, New Haven, Conn.

Disclosures: The authors reported no conflicts of interest.

The Journal policy requires editors and reviewers to disclose conflicts of interest and to decline handling or reviewing manuscripts for which they may have a conflict of interest. The editors and reviewers of this article have no conflicts of interest.

Received for publication Feb 28, 2021; revisions received Feb 28, 2021; accepted for publication March 1, 2021; available ahead of print March 4, 2021

Address for reprints: Arnar Geirsson, MD, Division of Cardiac Surgery, Yale School of Medicine, BB204, 330 Cedar St, PO Box 208039, New Haven, CT 06510 (E-mail: arnar.geirsson@yale.edu).

JTCVS Techniques 2021;7:157-8

2666-2507

Copyright (C) 2021 The Authors. Published by Elsevier Inc. on behalf of The American Association for Thoracic Surgery. This is an open access article under the CC BY-NCND license (http://creativecommons.org/licenses/by-nc-nd/4.0/).

https://doi.org/10.1016/j.xjtc.2021.03.007
}

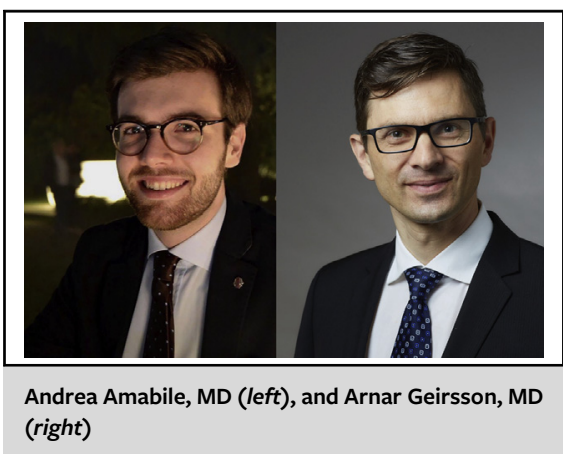

CENTRAL MESSAGE

Retained rotational atherectomy

device is a challenge surgeons

rarely face. Removal requires in-

ventive antegrade and/or retro-

grade approaches with

concomitant surgical

revascularization.

elongated longitudinally and then bypassed with a vein conduit. Although the authors divided the drive shaft and retrieved it in a 2-step fashion (1 part through the aortotomy intraoperatively and 1 part from the femoral artery postoperatively), they also recognized that retrieval can be thoroughly achieved peripherally, without the need to perform an aortotomy.

Entrapment during RA occurs in relation to the presence of a diamond coating on the front, but not the back, of the bullet-shaped burr, which does not allow for retrograde ablation. Thus, if the burr passes distally to a narrow, unablated segment of a calcified plaque, proximal movements become impaired, and the device may be impossible to retrieve. A burr-to-artery diameter ratio of 0.5 to 0.6 and gradual burr advancement with a pecking motion have been reported to help avoid entrapment, ${ }^{8}$ but the incidence of burr entrapment still ranges from $0.5 \%$ to $1 \%$ of RA series. ${ }^{9}$

This complication is usually unraveled in a catheterbased fashion with several techniques (detailed elsewhere), which include balloon angioplasty (immediately proximal to the burr via the same or a coaxial guide catheter) and deep catheter intubation. ${ }^{8}$ Nevertheless, cardiac surgery consultation becomes mandatory if retrieval is unsuccessful and if severe coronary dissection or perforation occur simultaneously, with the dual goal of both retrieving the device and providing the area of myocardium downstream with collateral blood supply. 
Waterford and colleagues ${ }^{7}$ must be congratulated for enriching the existing literature on this topic with an additional case report, and for simultaneously summarizing technical pearls for the surgical management of this rare, yet potentially severe, complication.

\section{References}

1. Lee MS, Yang T, Lasala J, Cox D. Impact of coronary artery calcification in percutaneous coronary intervention with paclitaxel-eluting stents: two-year clinical outcomes of paclitaxel-eluting stents in patients from the ARRIVE program. Catheter Cardiovasc Interv. 2016:88:891-7.

2. Vavuranakis M, Toutouzas K, Stefanadis C, Chrisohou C, Markou D, Toutouzas P. Stent deployment in calcified lesions: can we overcome calcific restraint with high-pressure balloon inflations? Catheter Cardiovasc Interv. 2001;52:164-72.
3. Shimony A, Zahger D, Van Straten M, Shalev A, Gilutz H, Ilia R, et al. Incidence risk factors, management and outcomes of coronary artery perforation during percutaneous coronary intervention. Am J Cardiol. 2009;104:1674-7.

4. Fitzgerald PJ, Ports TA, Yock PG. Contribution of localized calcium deposits to dissection after angioplasty. An observational study using intravascular ultrasound. Circulation. 1992;86:64-70.

5. Virmani R, Farb A, Burke AP. Coronary angioplasty from the perspective of atherosclerotic plaque: morphologic predictors of immediate success and restenosis. Am Heart J. 1994;127:163-79.

6. Ritchie JL, Hansen DD, Intlekofer MJ, Hall M, Auth DC. Rotational approaches to atherectomy and thrombectomy. Z Kardiol. 1987;76(Suppl 6):59-65.

7. Waterford SD, Suleman UJ, Sharma S, Filsoufi F. Surgical removal of rotational atherectomy device. J Thorac Cardiovasc Surg Tech. 2021;7:153-6.

8. Tomey MI, Kini AS, Sharma SK. Current status of rotational atherectomy. JACC Cardiovasc Interv. 2014;7:345-53.

9. Barbato E, Carrié D, Dardas P, Fajadet J, Gaul G, Haude M, et al. European expert consensus on rotational atherectomy. EuroIntervention. 2015;11:30-6. 